\title{
THE ACIDOSIS OF GUANIDINE INTOXICATION ${ }^{1}$
}

\author{
By A. S. MINOT, KATHARINE DODD AND J. M. SAUNDERS
}

(From the Department of Pediatrics, Vanderbilt University Medical School, Nashville)

(Received for publication July 13, 1934)

Recent reports (1) (2) (3) (4) (5) which implicate guanidine intoxication as a complicating factor in some instances of acute liver injury, of eclampsia, and of alimentary intoxication in infants, make it desirable to know in greater detail the effect of guanidine on various biological processes. Only in this way can we know in what manner increased guanidine may modify the clinical picture in a given disease and may influence the response of the patient to treatment of his symptoms. Since acidosis must often be treated in the presence of hyperguanidinemia, it is of interest to study the effect of guanidine intoxication on the acid base equilibrium.

Various observers have mentioned breathing of the "air hunger" type in guanidine poisoning. Watanabe (6) reported a decrease in $\mathrm{pH}$ and $\mathrm{CO}_{2}$ of the blood and an increased output of ammonia in the urine of experimental animals poisoned with guanidine. His results were disputed by György and Vollmer (7) who argued that a condition of alkalosis rather than acidosis must be produced since the hyperirritability caused by guanidine can be relieved by the administration of acid. These authors, however, presented no studies of acid base equilibrium to substantiate their claims. We already have considerable evidence that one feature of the intoxication is a serious disturbance of lactic acid metabolism. In an investigation of the hypoglycemia induced by guanidine and by its derivative synthalin, Staub (8) showed that lactic acid accumulates in the tissues and body fluids and is excreted in the urine. He attributes this accumulation to the inability of tissues poisoned with guanidine to oxidize and resynthesize lactic acid to its precursors in a normal manner. Gradually more and more of the carbohydrate reserve is transformed to lactic acid until a severe hypoglycemia results. Minot (9) confirmed these observations both in experimental guanidine poisoning and in the intoxication which occurs when hyperguanidinemia is a result of acute extensive necrosis of the liver. Although no acid base studies were reported in connection with either of these investigations one would expect that, as lactic acid accumulates and is neutralized, there would be a progressive depletion of the alkali reserve.

1 This work was aided by a grant from the Division of Medical Sciences of the Rockefeller Foundation. 
In order to study the effect of guanidine on the acid base balance of the subject or on his response to medication, it is necessary to use animals with experimental poisoning. Here one can observe the intoxication uncomplicated by disease and can study the response to a single form of medication.

\section{EXPERIMENTAL}

Intoxication was produced in dogs by the subcutaneous injection of guanidine hydrochloride. Because of the marked influence which the state of calcium nutrition has on susceptibility to guanidine poisoning, the dogs were kept on uniform diets for three or four weeks before the experiments were started. The diet of raw lean beef without bones was low in calcium. As a rule the dogs showed typical severe intoxication following the administration of two or three daily doses of $100 \mathrm{mgm}$. of guanidine hydrochloride per kilo of body weight. Three or four times as many such doses are required to produce the same severity of intoxication in dogs on a high calcium intake. Determinations of $\mathrm{pH}, \mathrm{CO}_{2}$ content, lactic acid, sugar, nonprotein nitrogen and guanidine were carried out on samples of blood as the intoxication progressed. The determinations were made by the following methods : $\mathrm{pH}$ by the colorimetric technique described by Cullen (10), $\mathrm{CO}_{2}$ by the manometric method of Van Slyke and Neill (11), lactic acid by the method of Friedemann and Kendall (12), sugar by Benedict's method (13), nonprotein nitrogen according to Folin and $\mathrm{Wu}(14)$, and guanidine by the colorimetric technique of Major and Weber (15), as modified by Minot and Dodd (1).

A marked fall in the $\mathrm{pH}$ and alkali reserve of the blood was invariably found to occur when the intoxication became severe. Traces of acetone were occasionally found in the urine and in some instances a retention of nitrogen indicated a nephritis which may have contributed to the acidosis. The most consistent finding, however, was a marked increase in the lactic acid content of blood and urine. We apparently had an acidosis due mainly to the replacement of bicarbonate of the body fluids by lactate. The highest concentrations of lactate in the blood were found during periods in which fibrillary tremors and convulsive twitching greatly increased the muscular activity. Although increased production was in these instances an obvious cause for the accumulation 'of lactic acid, defective metabolism appeared also to be a factor as there was but little tendency for the lactic acid in the blood to return to a normal level even after the subject had remained quiet for a long time. Sometimes there was depression rather than hyperirritability throughout the period of intoxication but still there was a marked increase in lactic acid. These experiments emphasize further the point already made by Staub (8) and by Minot (9) that lactic acid is not metabolized normally in guanidine intoxication.

In Table I data are presented showing the increase in lactic acid in the 
A. S. MINOT, RATHARINE DODD AND J. M. SAUNDERS

\begin{tabular}{|c|c|c|c|c|c|c|c|c|}
\hline & 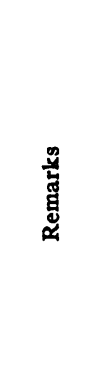 & & 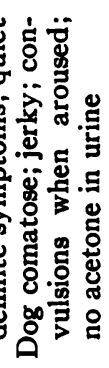 & 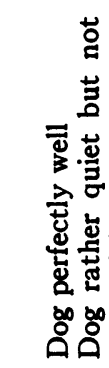 & 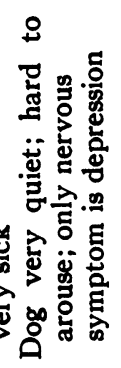 & 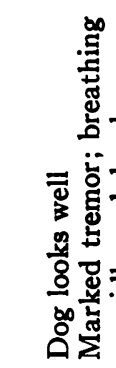 & 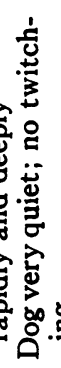 & 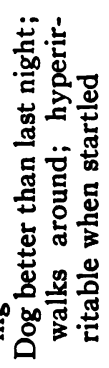 \\
\hline 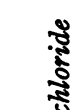 & 竭 & 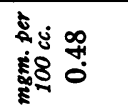 & 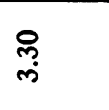 & 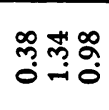 & กั & îّ & $\stackrel{\mathscr{\infty}}{\infty}$ & 욱 \\
\hline है & 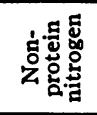 & 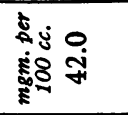 & & 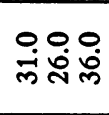 & 용 & 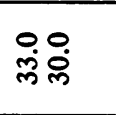 & 웅 & 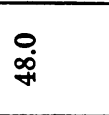 \\
\hline 胥 & 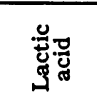 & 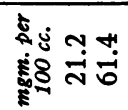 & : & $\begin{array}{l}0 \\
\infty \\
\infty\end{array}$ & $\ddot{\text { n }}$ & 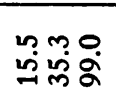 & $\underset{T}{T}$ & $\begin{array}{l}\text { : } \\
\text { : }\end{array}$ \\
\hline 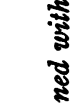 & 兽 & 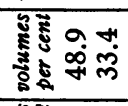 & $\ddot{\sim}$ & 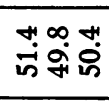 & 옹 & 我 & $\stackrel{m}{\text { i }}$ & $\overrightarrow{\text { స్ల }}$ \\
\hline हू & 今ేర్లే & 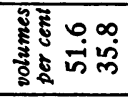 & $\underset{\Xi}{\sharp}$ & 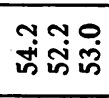 & 只 & ம் & 我 & लें \\
\hline हี & 急 & & ầ & 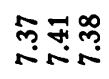 & $\stackrel{0}{2}$ & ڤ్తి & $\stackrel{\infty}{\circ}$ & ঙ্ণ \\
\hline 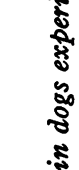 & $\stackrel{\Xi}{g}$ & 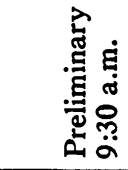 & $\begin{array}{c}\dot{\varepsilon} \\
\dot{0} \\
\stackrel{n}{\ddot{n}}\end{array}$ & 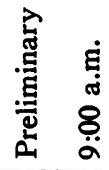 & $\begin{array}{c}\dot{g} \\
\dot{2} \\
\text { in } \\
\ddot{j}\end{array}$ & 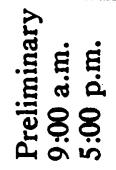 & 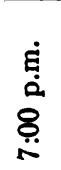 & $\begin{array}{l}\dot{g} \\
\text { jं } \\
\text { ઠे } \\
\dot{a}\end{array}$ \\
\hline 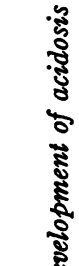 & ڤั & 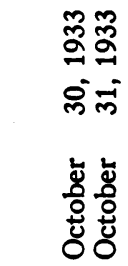 & 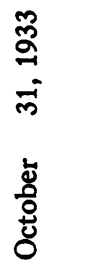 & 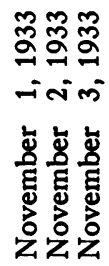 & 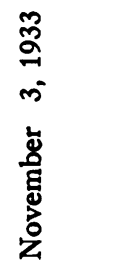 & 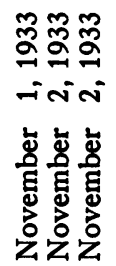 & & 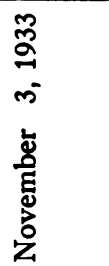 \\
\hline & 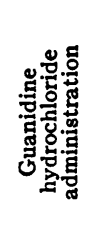 & 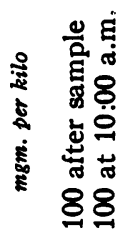 & & 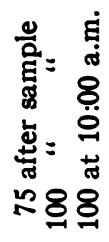 & & 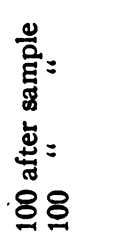 & & \\
\hline & 乫产 & $\rightarrow$ & & N & & $m$ & & \\
\hline
\end{tabular}




\begin{tabular}{|c|c|c|c|c|c|}
\hline 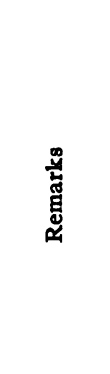 & 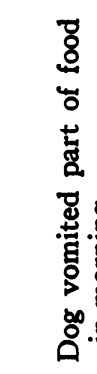 & 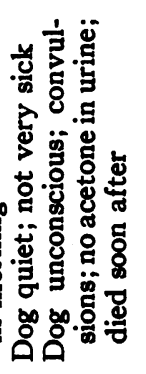 & 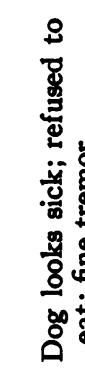 & 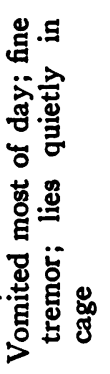 & 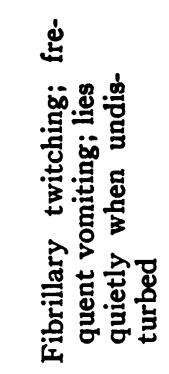 \\
\hline 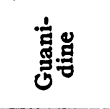 & 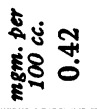 & 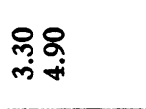 & $\stackrel{\infty}{m}$ & $\stackrel{9}{ }$ & $\begin{array}{l}98 \\
0+4 \\
0\end{array}$ \\
\hline 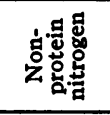 & 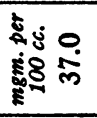 & $\stackrel{8}{80}$ & 웅 & 옳 & 망요 \\
\hline 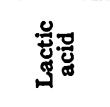 & 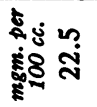 & ণิં & 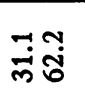 & 官 & تㅇํㅇ \\
\hline 莡 & 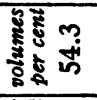 & مُ & 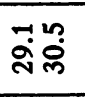 & 己ై & ฝึં \\
\hline త్రేర్ర & 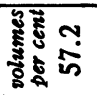 & 車 & 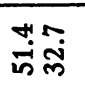 & $\underset{\text { ஸे }}{\text { ஸे }}$ & 它 \\
\hline 罢 & 旁 & 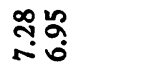 & 永 & $\stackrel{\overbrace{}}{\sim}$ & గ్రి \\
\hline \multirow[b]{2}{*}{ 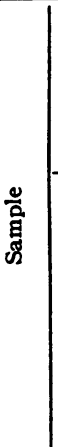 } & 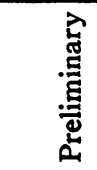 & 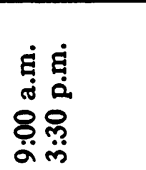 & 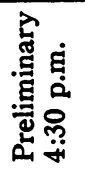 & $\begin{array}{l}\dot{g} \\
\dot{0} \\
\stackrel{\leftrightarrow}{\dot{+}}\end{array}$ & 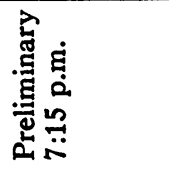 \\
\hline & 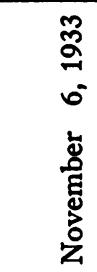 & 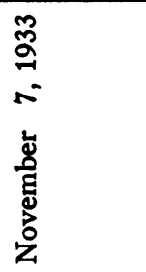 & 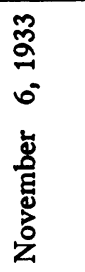 & 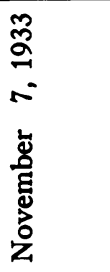 & 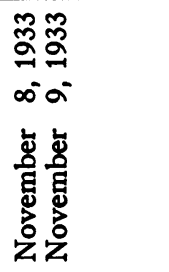 \\
\hline 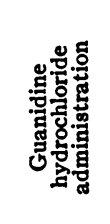 & 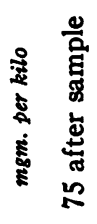 & $\begin{array}{l}= \\
= \\
20\end{array}$ & 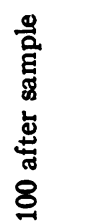 & 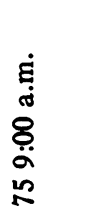 & 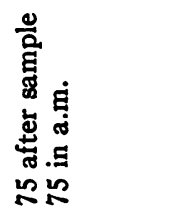 \\
\hline 吅眖 & + & & in & & 0 \\
\hline
\end{tabular}


blood and the degree of acidosis present in acute experimental guanidine poisoning. Although a large group of animals have been studied data from only six typical experiments are included as further figures of the same kind appear incidentally in other tables in this paper. It is apparent from the figures presented that there is a tendency for the $\mathrm{pH}$ of the blood to fall considerably while the alkali reserve is still not greatly reduced. This tendency has been observed repeatedly throughout our study of the acidosis of guanidine poisoning. The fall in $\mathrm{pH}$ may be associated with a depression of the respiratory center, since some subjects with severe acidosis fail to show increased respiration of the "air hunger" type. Circulatory disturbances which are now being investigated may also play a considerable rôle in allowing free $\mathrm{CO}_{2}$ to accumulate in the blood.

Hartmann and Senn (16) (17) (18) have recently reported that the utilization of sodium r-lactate administered intravenously furnishes base to increase the alkali reserve in normal and acidotic subjects. If the acidosis of guanidine poisoning is due primarily to an inability to metabolize lactic acid of endogenous origin there should also be a poor utilization of administered lactate. Experiments were planned to compare the effectiveness of sodium lactate with that of other therapeutic measures in the treatment of the acidosis produced in animals by the administration of guanidine.

It seemed necessary before we could give much weight to observations in regard to the utilization of lactate by dogs poisoned with guanidine to study the effect of similar doses of lactate on normal dogs and on dogs with other types of acidosis. The dose of molar solution of sodium lactate administered in each case was calculated, according to the formula given by Hartmann and Senn (16), to raise the alkali reserve of the body fluids by 20 volumes per cent. The solution was diluted with 2 to 3 volumes of water and injected into a leg vein. In a few instances when death from hypoglycemia seemed imminent 5 per cent glucose solution was used as a diluent. Blood for analysis was drawn with as little stasis as possible from the external jugular vein before and at hourly intervals after the administration of lactate. The bladder was emptied before the lactate was given and the catheter kept in place so that samples of urine could be obtained corresponding to the blood samples which were taken. The bicarbonate and lactate content of the urine was determined. Only the data showing the effect on the blood chemistry and the amount of lactate excreted unchanged in the urine are included in Table II. Typical experiments from each group of studies are presented.

Most of the increase in alkali reserve of the blood occurred during the first hour after the lactate was injected but a slight additional rise was sometimes noted in the second or third hour. The lactate in the blood had usually returned to approximately the normal level by the end of three hours. In ten normal dogs the increase in alkali reserve in the blood in 


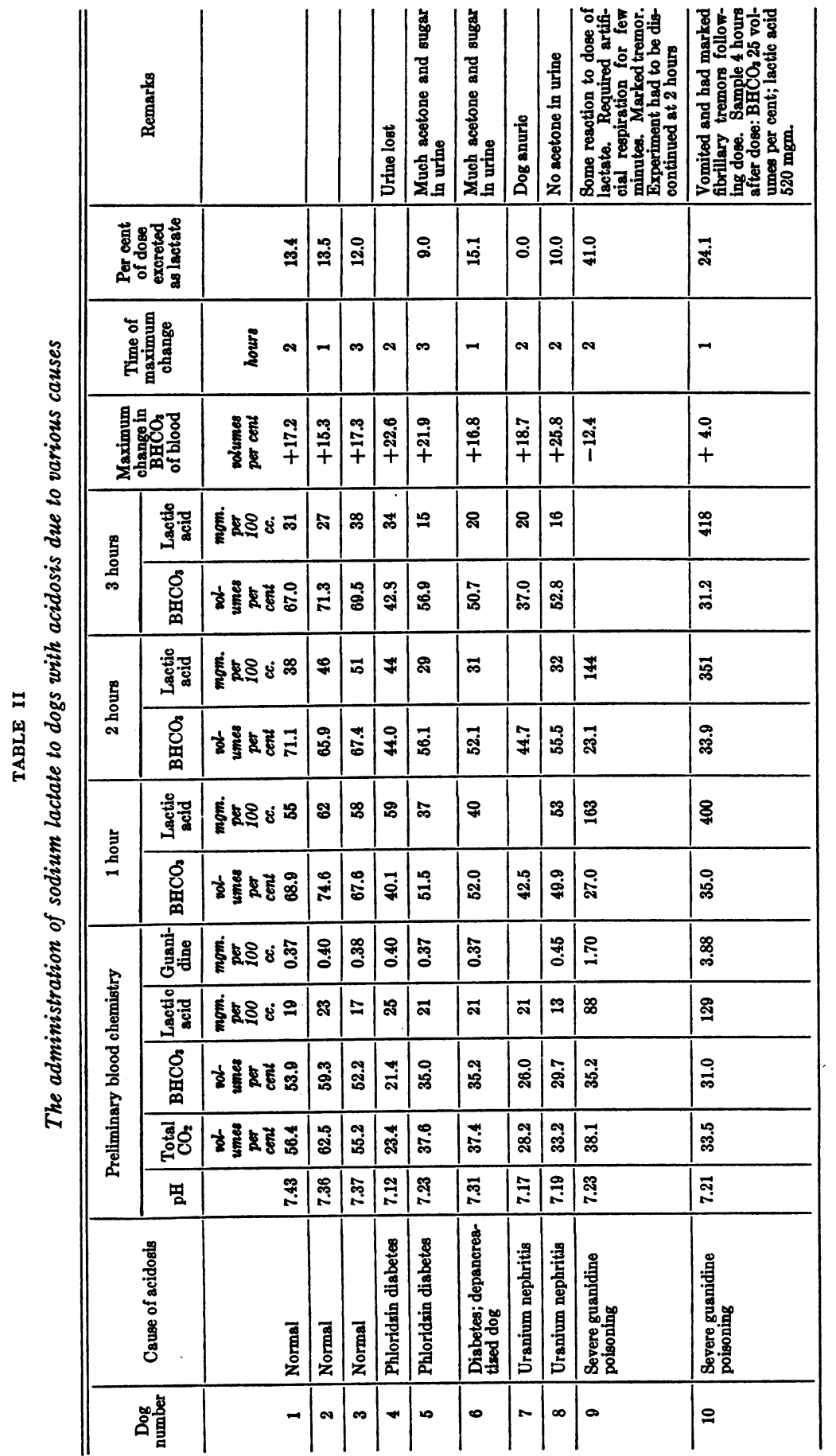


A. S. MINOT, KATHARINE DODD AND J. M. SAUNDERS

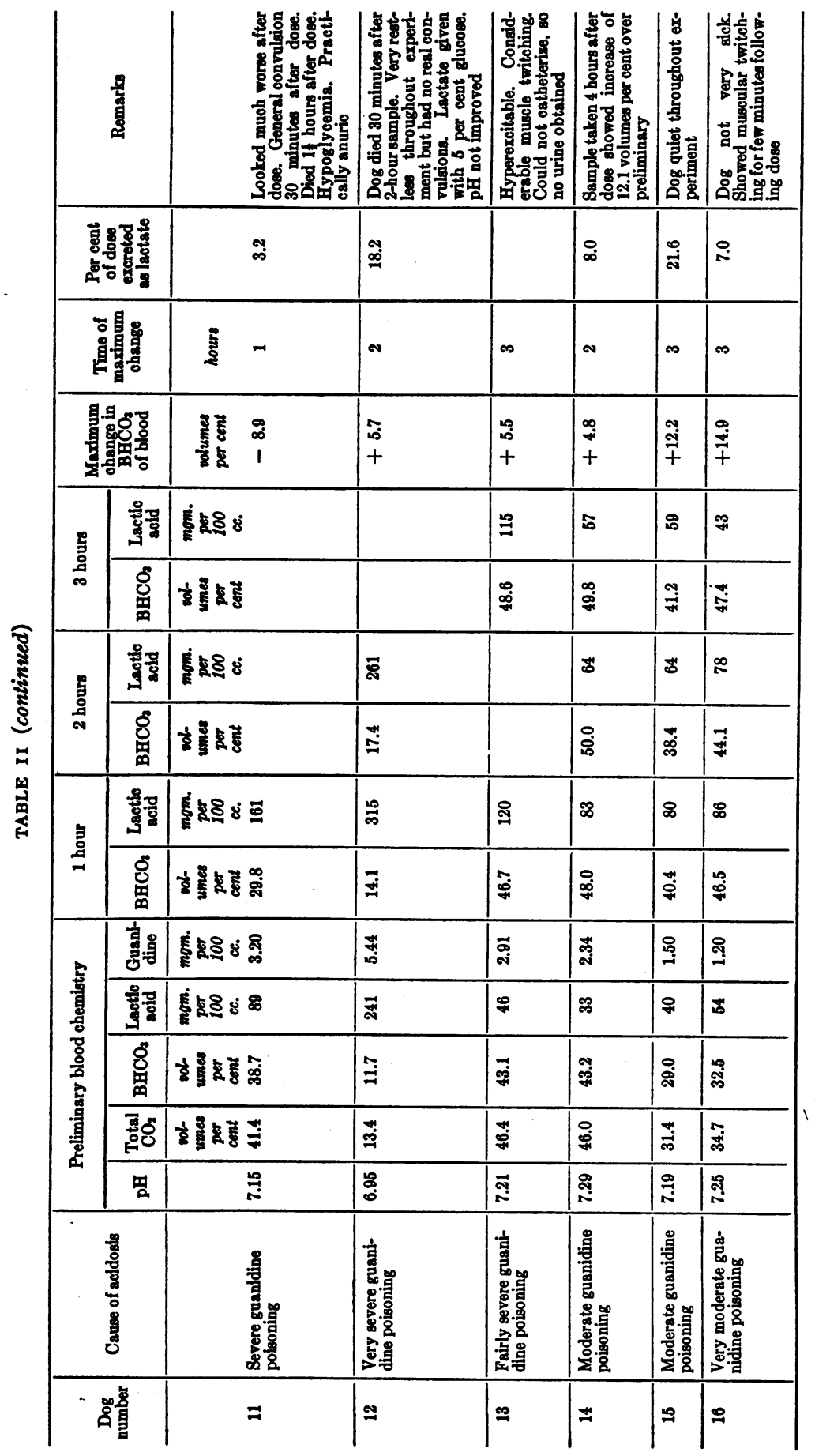


no case reached the calculated 20 volumes per cent. From ten to twenty per cent of the dose of lactate was excreted unchanged in the urine. The small discrepancy between the observed rise in $\mathrm{BHCO}_{3}$ and that to be expected from the utilized lactate can be accounted for by bicarbonate excreted in the urine when the already normal level of $\mathrm{BHCO}_{3}$ in the blood was raised above the renal threshold for bicarbonate. When all these factors are taken into consideration one can account for the disposal of the administered lactate with surprising exactness, considering the roughness of the approximations involved in the calculations.

Ketone body acidosis was produced in ten dogs by the administration of phloridzin and in one by complete removal of the pancreas. The phloridzinized animals usually showed slightly more than the calculated rise in alkali reserve following the administration of sodium lactate. The overcorrection was probably due to the fact that as the lactate was utilized, glucose became available and base bound with ketone bodies as well as that introduced as lactate served to increase the alkali reserve. The overcorrection became much more marked if the lactate was given with glucose solution. When lactate was administered to the dog with ketone body acidosis following complete pancreatectomy the overcorrection did not occur.

Acidosis secondary to severe nephritis was produced in 8 dogs by the subcutaneous injection of uranium nitrate as described by MacNider (19). A dose of sodium lactate calculated to increase the alkali reserve 20 volumes per cent was then administered intravenously as in the experiments already described. The data show a prompt utilization of injected lactate and a corresponding increase in the alkali reserve. In some instances there was a markedly increased urinary flow following the intravenous injection of fluid in subjects which had been practically anuric. The improved kidney function apparently resulted in the excretion of considerable acid so that the increase in alkali reserve was slightly greater than the expected rise.

The preliminary experiments are in accord with the reports of Hartmann and Senn. Approximately the calculated increase in $\mathrm{BHCO}_{3}$ of the blood results from the intravenous administration of sodium lactate to normal dogs and to dogs with nephritic or ketone body acidosis.

The same doses of sodium lactate were much less effective in raising the alkali reserve in animals with guanidine poisoning. In subjects with a moderate degree of intoxication the utilization of lactate was slow and incomplete. In severe intoxication there was only a slight rise or at times a fall in the alkali reserve of the blood. Unless there was oliguria due to nephritis or to previous dehydration, a considerable portion of the dose was excreted unchanged in the urine. The lactic acid content of the blood remained high. The rather abrupt fall in alkali reserve observed in some instances was accompanied by an increase in the objective symptoms of 
guanidine intoxication. Severe twitching of the muscles or occasionally generalized convulsions appeared following the injection of lactate. The muscular activity increased the production of lactic acid which was poorly metabolized and further reduced the alkali reserve. Even when no convulsive symptoms were produced there was often a general exacerbation of the intoxication and little or no change in the alkali reserve. The probable reason for this deleterious effect of lactate will be discussed later in this paper. The experiments just described support the hypothesis that the acidosis of guanidine poisoning is primarily due to an inability to metabolize lactic acid of endogenous origin and show the futility of attempting to correct this acidosis by the administration of base in the form of sodium lactate.

Obviously sodium bicarbonate would be directly available and, if it could be administered without untoward reactions, would be a more effective form of medication than sodium lactate. A considerable number of preliminary experiments with normal animals and with subjects with acidosis secondary to accumulation of ketone bodies and to nephritis showed that sodium bicarbonate in doses sufficient to raise the alkali reserve of the body fluids 20 volumes per cent $(20)$ could be administered intravenously without the production of untoward symptoms. This was true even when the dose raised the base bicarbonate of the blood well above normal limits. The animals were able to make adjustments so that only a temporary compensated alkalosis was produced. In an occasional nephritic subject with anuria uncompensated alkalosis accompanied by more or less severe tetany was sometimes observed.

It soon became apparent that the administration of sodium bicarbonate to animals with severe guanidine intoxication was attended by considerable danger. The injection of a solution of this salt regularly produced an exacerbation of the symptoms of intoxication greater than that which had been observed following the administration of sodium lactate. There was often twitching of the muscles throughout the observation period and frequently there were generalized convulsions. The production of lactic acid by increased activity was so great and the disposal of lactate so defective that the alkali reserve in the blood was often further decreased an hour or two after the administration of sodium bicarbonate. Other characteristic manifestations of guanidine intoxication such as vomiting, diarrhea, and a tendency to hypoglycemia were also aggravated by bicarbonate medication. In less severe intoxication the symptoms following the injection were of the same nature but were transient and not alarming. Only in subjects with so mild a degree of intoxication that alkali therapy was hardly necessary could sodium bicarbonate solution be injected without the production of untoward symptoms. In these instances the base bicarbonate of the blood was increased by about the calculated amount.

Excess alkalinity of the blood as a cause of the undesirable reaction was 
ruled out by determination of $\mathrm{pH}$ and $\mathrm{CO}_{2}$ on additional samples of blood drawn soon after the injection of the sodium bicarbonate and at the height of the convulsive symptoms. Apparently the administration of sodium bicarbonate had suddenly increased the toxic action of guanidine. A similar reaction was described by Minot, Dodd, and Bryan (21) following the administration of sodium citrate to animals with hyperguanidinemia. An effect similar though somewhat less severe following the injection of sodium lactate was also noted earlier in this paper. The antagonism between the action of guanidine and calcium ions has been repeatedly emphasized (2) (9) (22) (23) (24). The injection of any sodium salt upsets the ionic balance of the blood by the introduction of a disproportionate amount of sodium ions. When sodium bicarbonate or citrate is administered there is, besides the excess of sodium, a depression of the ionization of the calcium in the blood. This temporary decrease in the effect of calcium ions is of no moment in a normal animal but becomes serious in the presence of increased amounts of guanidine.

If this explanation is correct the obvious method of preventing and relieving this undesirable reaction to therapy would be to combine calcium medication with the administration of alkali. Previous work (9) has shown that calcium medication alone prevents the accumulation of lactic acid in animals following the administration of guanidine. The two following protocols show the gradual decrease in lactate and increase in alkali reserve in the blood resulting from repeated intravenous injections of calcium gluconate in subjects previously made acidotic as a result of intoxication with guanidine hydrochloride:

Dog Number 1.

Received $100 \mathrm{mgm}$. per kilo of guanidine hydrochloride subcutaneously daily on 2 preceding days.

November 4, 1933. Shows vomiting and diarrhea, marked incoordination and weakness, cannot stand but lies quietly on side.

9 a.m. $\mathrm{pH} 7.17 ; \mathrm{CO}_{2}$ content 34.0 volumes per cent; alkali reserve 31.4 volumes per cent; lactic acid $74 \mathrm{mgm}$. per $100 \mathrm{cc}$; guanidine 2.27 mgm. per $100 \mathrm{cc}$.

9:15 a.m. 15 cc. 7.5 per cent calcium gluconate intravenously.

10:30 a.m. 15 cc. 7.5 per cent calcium gluconate intravenously. Dog stands up looking much better.

$12: 00$ noon. $\mathrm{pH} 7.25 ; \mathrm{CO}_{2}$ content 40.3 volumes per cent; alkali reserve 37.7 volumes per cent; lactic acid $64 \mathrm{mgm}$. per $100 \mathrm{cc}$.

$1: 00$ p.m. 15 cc. 7.5 per cent calcium gluconate intravenously.

$3: 30$ p.m. pH 7.27; $\mathrm{CO}_{2}$ content 43.3 volumes per cent; alkali reserve 39.5 volumes per cent; lactic acid $50 \mathrm{mgm}$. per $100 \mathrm{cc}$; guanidine 2.40 mgm. per $100 \mathrm{cc}$. 
Summary. As a result of 6 hours of intensive calcium medication the $\mathrm{pH}$ of the blood increased from 7.17 to 7.27 ; the alkali reserve rose from 31.4 volumes per cent to 39.5 volumes per cent; the lactic acid fell from 74 to $50 \mathrm{mgm}$. per $100 \mathrm{cc}$; t the guanidine concentration remained practically the same being $2.27 \mathrm{mgm}$. per $100 \mathrm{cc}$. in the first sample and $2.40 \mathrm{mgm}$. per $100 \mathrm{cc}$. in the last.

\section{Dog Number 2.}

November 6, 1933. Received $100 \mathrm{mgm}$. per kilo of guanidine hydrochloride subcutaneously.

November 7, 1933. 9 a.m. Received $50 \mathrm{mgm}$. per kilo of guanidine hydrochloride subcutaneously. Dog vomited at frequent intervals during the day, had fine fibrillary tremors of muscles but no gross convulsive movements.

4:00 p.m. $\mathrm{pH} 7.23 ; \mathrm{CO}_{2}$ content 28.2 volumes per cent; alkali reserve 26.3 volumes per cent; lactic acid $88 \mathrm{mgm}$. per $100 \mathrm{cc}$; guanidine $4.10 \mathrm{mgm}$. per $100 \mathrm{cc}$.

5 p.m. 15 cc. 7.5 per cent calcium gluconate intravenously.

7:00 p.m. pH 7.25; $\mathrm{CO}_{2}$ content 32.9 volumes per cent; alkali reserve 30.6 volumes per cent; lactic acid $59 \mathrm{mgm}$. per $100 \mathrm{cc}$.

7:10 p.m. $15 \mathrm{cc} .5$ per cent calcium gluconate intravenously.

9:00 p.m. pH 7.25; $\mathrm{CO}_{2}$ content 33.0 volumes per cent; alkali reserve 30.8 volumes per cent; lactic acid $51 \mathrm{mgm}$. per $100 \mathrm{cc}$.

9:10 p.m. 15 cc. 7.5 per cent calcium gluconate intravenously.

November 8, 1933. 9 a.m. Dog looking much better, still some fibrillary tremor. $\mathrm{pH} 7.29 ; \mathrm{CO}_{2}$ content 47.4 volumes per cent; alkali reserve 44.5 volumes per cent; lactic acid $45 \mathrm{mgm}$. per $100 \mathrm{cc}$; guanidine 3.00 mgm. per $100 \mathrm{cc}$.

Summary. There was a gradual increase in $\mathrm{pH}$ from 7.23 to 7.29 ; in alkali reserve from 26.3 to 44.5 volumes per cent, and a decrease in lactic acid from 88 to $45 \mathrm{mgm}$. per $100 \mathrm{cc}$. during 16 hours of calcium medication. The concentration of guanidine in the blood decreased from 4.10 to $3.00 \mathrm{mgm}$. per $100 \mathrm{cc}$. during this interval.

Experiments were also carried out in which calcium medication was combined with the administration of sodium lactate. In these instances no increase in irritability was noted following the injection of lactate. When two consecutive experiments were done on the same animal, giving sodium lactate alone in the first, and sodium lactate plus repeated doses of calcium in the second, a greater increase in alkali reserve usually resulted in the second experiment. The increase during the observation period of three hours following medication was not striking, however, and was only about the same as when calcium was administered alone. As long as lactate of endogenous origin is present in abnormally high concentration in the blood there is little rationale to the administration of more lactate. 
Experiments were then carried out in which calcium therapy was combined with the administration of sodium bicarbonate. Typical results obtained in these experiments are included in Table III. When calcium medication is adequate the undesirable reaction following the administration of sodium bicarbonate does not occur, and practically the calculated increase in the alkali reserve of the blood is produced. It is difficult to state exactly the amounts of calcium which constitute adequate therapy. The severity of the intoxication, the state of calcium nutrition, and the size of the subject all influence the dose required. Our usual procedure with experimental animals was to give $10 \mathrm{cc}$. of a ten per cent solution of calcium gluconate ${ }^{2}$ before the administration of the bicarbonate and repeated smaller doses (usually $5 \mathrm{cc}$.) of the same solution whenever the reappearance of tremor indicated that more was necessary. When the hyperirritability is not adequately controlled by calcium, as was the case in Subject 5 in Table III, there is incomplete correction of the acid base equilibrium by the sodium bicarbonate. Even when calcium is administered one must guard against hypoglycemia which is so constant a feature of severe guanidine intoxication. For this reason we have found it advantageous to administer the sodium bicarbonate dissolved in a 5 per cent glucose solution.

It was noted that a considerable decrease in the degree of hyperguanidinemia resulted whenever medication involved the intravenous injection of considerable amounts of fluid. This decrease was associated with a marked increase in the output of urine. Glucose or sodium chloride solution was found as effective as alkalinizing salts in hastening the excretion of guanidine. A more detailed study in regard to the importance of fluid administration is in progress and will be reported later. In this paper we wish merely to point out that fluid administration to improve kidney function is an important feature whatever the specific means employed to combat the acidosis.

\section{DISCUSSION}

In the experiments just described the entire toxic picture was produced in otherwise normal animals by the administration of guanidine. The intoxication in these instances is therefore more severe than that which ordinarily develops as a complication in disease. An acidosis due primarily to guanidine is probably seldom, if ever, seen clinically. Similarly a less serious interference with treatment will as a rule be caused by amounts of guanidine which accumulate spontaneously. These results, nevertheless, indicate that whenever guanidine intoxication is a secondary factor in clinical disease it will to some extent favor the production of acidosis and complicate the treatment of that condition. Hyperguanidinemia is often

2 The calcium used was furnished by the Sandoz Chemical Works, Inc. 
A. S. MINOT, KATHARINE DODD AND J. M. SAUNDERS

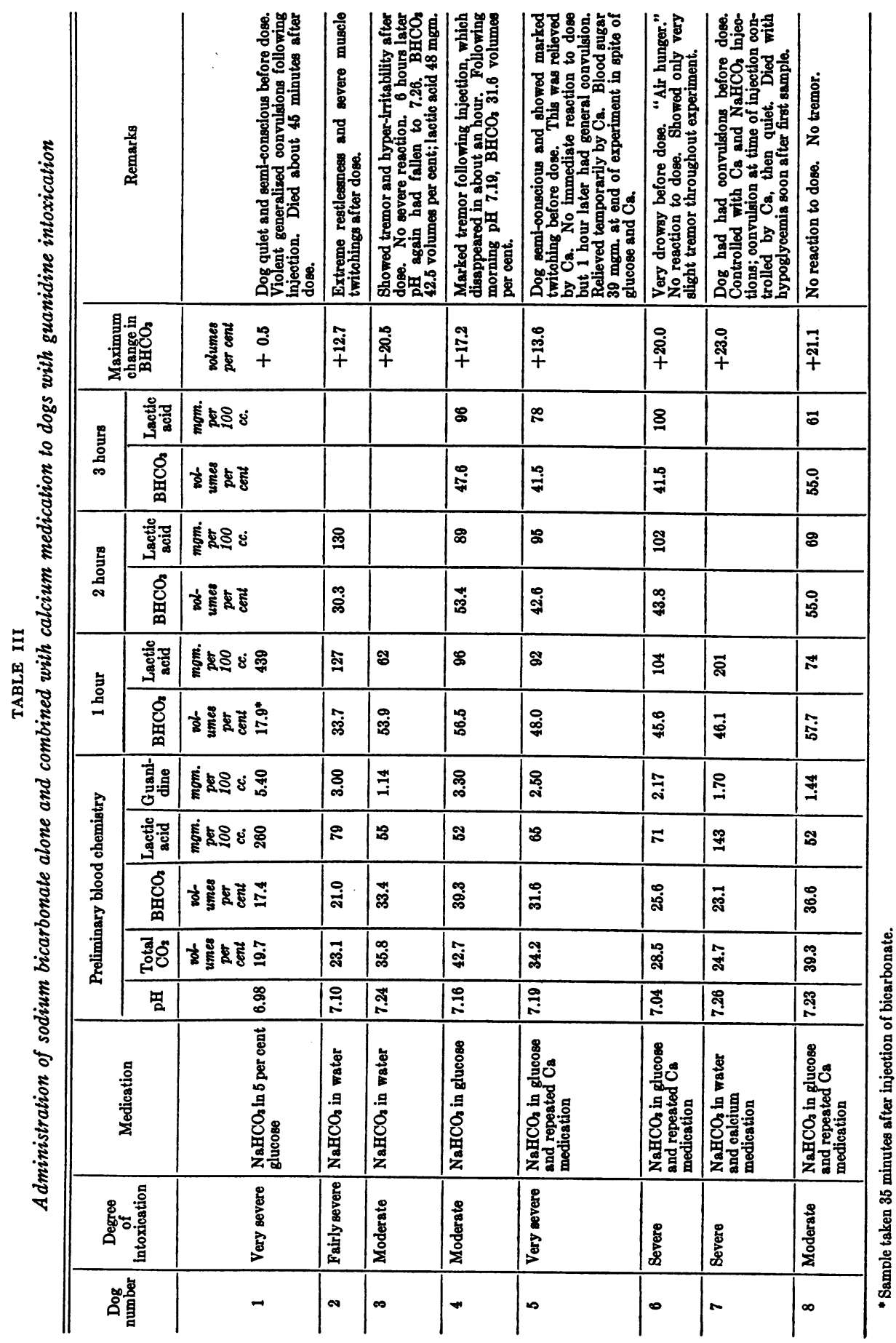


present in alimentary intoxication but certainly in this condition guanidine is at most but a secondary factor in the production of acidosis. The partial failure of subjects with alimentary intoxication to utilize lactates as reported by Hartmann and Senn (18) is probably due, at least in part, to an interference with metabolism due to guanidine. Quite possibly some of the undesirable reactions which have been ascribed to hyperalkalinity following the administration of sodium bicarbonate have in reality been due to a temporary increase in the toxic action of guanidine. Our experimental work with animals suggests that the addition of calcium therapy would make the administration of alkalinizing salts to patients with hyperguanidinemia safer and more effective. The removal of guanidine through increased kidney function may be an important feature in the adjustment of acid base equilibrium by continuous venoclysis with glucose or Ringer solution as advocated by Karelitz (25). We believe a combination of therapy consisting of forced parenteral fluids, calcium medication, and the administration of sodium bicarbonate is more satisfactory than any single procedure in the management of severe clinical acidosis complicated by guanidine intoxication.

SUMMARY

Guanidine intoxication has been shown to cause an acidosis due primarily to increased production and defective metabolism of lactic acid. The administration of alkalinizing sodium salts in the treatment of this acidosis is attended by unusual difficulties because of the danger associated with any temporary decrease in the effectiveness of calcium ions in the presence of increased guanidine. Sodium lactate fails to increase the alkali reserve because of the inability of the subject to utilize lactates. Sodium bicarbonate while at times both dangerous and ineffective if used alone, can be made safe and promptly efficient if calcium medication is combined with its administration. A very gradual relief of acidosis results from calcium medication alone or from the intravenous administration of fluid in the form of glucose solution or normal saline. The latter procedure also improves the condition of the subject by hastening the excretion of guanidine through improved kidney function. We have found the most satisfactory treatment of the acidosis produced by the administration of guanidine to be the use of sodium bicarbonate combined with repeated intravenous calcium medication and the injection of liberal amounts of fluids to increase the urinary output. The same form of treatment is recommended for severe acidosis in clinical subjects with hyperguanidinemia.

\section{BIBLIOGRAPHY}

1. Minot, A. S., and Dodd, K., Guanidine intoxication, a complicating factor in certain clinical conditions in children. Am. J. Dis. Child., 1933, 46, 522.

2. Dodd, K., and Minot, A. S., Incidental hyperguanidinemia as a cause of clinical tetany. Am. J. Dis. Child., 1934, 47, 958. 
3. Minot, A. S., and Cutler, J. T., Increase in guanidine-like substance in acute liver injury and eclampsia. Proc. Soc. Exper. Biol. and Med., $1929,26,607$.

4. Ellsworth, R., Guanidine base concentration in blood of normal individuals and in patients with liver injury. Bull. Johns Hopkins Hosp., 1930, 46, 296.

5. Titus, P., Messer, F. C., and McClellan, R. H., Increase of guanidine compounds in eclampsia: an experimental study. Am. J. Obst. and Gynec., $1932,24,667$.

6. Watanabe, C. K., Studies in the metabolic changes induced by administration of guanidine bases. III. The relation between the tetanoid symptoms of guanidine administration and the condition of acidosis. J. Biol. Chem., 1918, 34, 65.

7. György, P., and Vollmer, H., Beeinflussung der Guanidinvergiftung durch Säurezufuhr. Arch. f. exper. Path. u. Pharmacol., 1922, 95, 200.

8. Staub, H., Experimentelle Untersuchungen über Synthalinwirkung. Ztschr. f. klin. Med., 1928, 107; 607.

9. Minot, A. S., The mechanism of the hypoglycemia produced by guanidine and carbon tetrachloride poisoning and its relief by calcium medication. J. Pharmacol. and Exper. Therap., 1931, 43, 295.

10. Cullen, G. E., Studies of acidosis. XIX. The colorimetric determination of the hydrogen ion concentration of blood plasma. J. Biol. Chem., 1922, 52, 501.

11. Van Slyke, D. D., and Neill, J. M., The determination of gases in blood and other solutions by vacuum extraction and manometric measurement. I. J. Biol. Chem., 1924, 61, 523.

12. Friedemann, T. E., and Kendall, A. I., The determination of lactic acid. J. Biol. Chem., 1929, 82, 23.

13. Benedict, S. R., The estimation of sugar in blood and normal urine. J. Biol. Chem., 1926, 68, 759.

14. Folin, O., and $\mathrm{Wu}, \mathrm{H} ., \mathrm{A}$ system of blood analysis. J. Biol. Chem., 1919, 38,81 .

15. Major, R. H., and Weber, C. J., The probable presence of increased amounts of guanidine in the blood of patients with arterial hypertension. Bull. Johns Hopkins Hosp., 1927, 40, 85.

16. Hartmann, A. F., and Senn, M. J. E., Studies in the metabolism of sodium $r$-lactate. I. Response of normal human subjects to the intravenous injection of sodium $r$-lactate. J. Clin. Invest., 1932, 11, 327.

17. Hartmann, A. F., and Senn, M. J. E., Studies in the metabolism of sodium $r$-lactate. II. Response of human subjects with acidosis to the intravenous injection of sodium $r$-lactate. J. Clin. Invest., 1932, 11, 337.

18. Hartmann, A. F., and Senn, M. J. E., Studies in the metabolism of sodium $r$-lactate. III. Response of human subjects with liver damage, disturbed water and mineral balance, and renal insufficiency to the intravenous injection of sodium $r$-lactate. J. Clin. Invest., 1932, 11, 345.

19. MacNider, W. deB., A study of the action of various diuretics in uranium nephritis. J. Pharmacol. and Exper. Therap., 1911-12, 3, 423.

20. Palmer, W. W., and Van Slyke, D. D., Studies of acidosis. IX. Relationship between alkali retention and alkali reserve in normal and pathological individuals. J. Biol. Chem., 1917, 32, 499.

21. Minot, A. S., Dodd, K., and Bryan, R., Chemical action of sodium citrate as a cause of certain transfusion reactions. Am. J. Dis. Child., 1933, 45,32 . 
22. Minot, A. S., and Cutler, J. T., Guanidine retention and calcium reserve as antagonistic factors in carbon tetrachloride and chloroform poisoning. J. Clin. Invest., 1928, 6, 369.

23. Kühnau, J., and Nothmann, M., Ueber die Guanidintoxikose und ihre Beziehungen zur Tetanie. Ztschr. f. d. ges. exper. Med., 1924, 44, 505.

24. Clark, G. A., Interrelation of parathyroids, suprarenals and pancreas. J. Physiol., 1924, 58, 294.

25. Karelitz, S., and Schick, B., Treatment of toxicosis with the aid of a continuous intravenous drip of dextrose solution. Am. J. Dis. Child., 1931, $42,781$. 